\title{
How to Classify Type 2 Diabetes Mellitus and Approach its Treatment in View of Associated Diabetes and Complications-A Short Communication
}

\author{
Kaur KK ${ }^{1^{*}}$, Allahbadia $\mathbf{G}^{2}$ and Singh $\mathbf{M}^{3}$ \\ ${ }^{1}$ Dr. Kulvinder Kaur Centre for Human Reproduction, India \\ ${ }^{2}$ Rotunda, Centre for Human Reproduction, India \\ ${ }^{3}$ Swami Satyanand Hospital, India
}

${ }^{*}$ Correspondence: Kulvinder Kochar Kaur, Dr. Kulvinder Kaur Centre for Human Reproduction, India

Received on 06 June 2019; Accepted on 09 July 2019; Published on 23 July 2019

Copyright () 2019 Kaur KK, et al. This is an open access article and is distributed under the Creative Commons Attribution License, which permits unrestricted use, distribution, and reproduction in any medium, provided the original work is properly cited.

\begin{abstract}
With the increase in epidemic of obesity, the incidence of type 2 diabetes mellitus (T2DM) is increasing globally so much that the need has arisen for treating the two diseases together with the term diabesity getting coined. Here, we have tried to sub-classify T2DM stage-wise and how the treatment should be aimed keeping in view the use of weight-neutral anti-diabetic drugs. Preferably, insulin needs to be avoided due to its weight gaining effects and use of liraglutide should be preferred in the heavily obese diabetics due to its weight lowering effects. If the patient is in stage 4 group where insulin is practically non-existent, one can try using anti-obesity drugs along with insulin or see which works better with the influence of bariatric surgery seen on controlling diabetes in morbidly obese subjects.
\end{abstract}

Keywords: obesity, type 2 diabetes mellitus, diabesity, C-peptide, proliferative diabetic retinopathy, diabetic nephropathy, liraglutide, bariatric surgery

Abbreviations: PDR: proliferative diabetic retinopathy; T2DM: type 2 diabetes mellitus; DM: diabetes mellitus; FSG: fasting serum glucose; OGTT: oral glucose tolerance test; PG: postglucose; DKA: diabetic ketoacidosis; HHS: hyperosmolar hyperglycemic state; BOT: basal-supported oral therapy; OR: odds ratio; BS: blood sugar

\section{Introduction}

Recently we reviewed how the incidence of diabetes mellitus (DM) and obesity is increasing alarmingly due to which the term diabesity got coined and how one needs to treat these two together and gave some examples of the treatment [1-3].

Currently, no staging system exists for type 2 diabetes mellitus (T2DM). Wu in 2018 gave a staging system that would help clinicians along with patients in the better management of DM and might favourably affect the ultimate prognosis of diabetic subjects [4]. 


\section{The Proposed Classification}

Stage 1 or prediabetes includes that group of patients who were present with a fasting serum glucose (FSG) level of $105-125 \mathrm{mg} / \mathrm{dl}(5.6-6.6 \mathrm{mM})$ (altered fasting glucose), along with the following intake of $75 \mathrm{~g}$ glucose on $2 \mathrm{~h}$ oral glucose tolerance test (OGTT) present with serum glucose (SG) level of 140-199 mg/dl (7.8-11.0 mM) (impaired glucose tolerance), haemoglobin A1c (HbA1c) level of 5.7-6.4\% [5, 6]. This stage is irrespective of comorbidities like hypertension, dyslipidemia, and overweight and requires treatment of any comorbidity, counseling for prevention of DM development by lifestyle modifications that include nutritional advice, weight loss strategies along with control of hypertension, dyslipidemia.

Stage 2 or overt diabetes includes that group where overt DM is not associated with any complications. Here subjects present with FSG $\geq 126 \mathrm{mg} / \mathrm{dL}(7.0 \mathrm{~mm}), 2 \mathrm{~h}$ postglucose $(\mathrm{PG})$ level on OGTT of $\geq 200 \mathrm{mg} / \mathrm{dL}(11.1 \mathrm{mM}), \mathrm{HbA} 1 \mathrm{c}$ level $\geq 6.5 \%$, a typical problem associated with high levels of sugar, or a random PG level of $\geq 200 \mathrm{mg} / \mathrm{dl}(11.1 \mathrm{mM})$ [5, 7-9]. There might be a presence of decreased insulin sensitivity in these subjects.

Clinically stage 2 might be associated with mild disorders, like acanthosis nigricans, raised blood pressure (BP), disordered lipid profile besides development of Stein-Leventhal syndrome/(PCOS) or intrauterine growth retardation =>low birth weight infants [5]. Management principles are the same i.e., i) basic lifestyle interventions, ii) nutritional advice along with controlling the hyperglycemia with oral anti-diabetic drugs. Treatment can either be started with metformin or biguanides, or addition of insulin might even be needed. The basic aim is to prevent the development of any DM complications. Thus initially a baseline urine status, fundus examination, renal function test needs to be performed to further monitor for complication development along with treating comorbidities. As far as possible, try to initiate treatment with weight neutral drugs and avoid insulin in T2DM with its weight-promoting actions in view of obesity co-existing with T2DM and the vicious effects of weight-promoting anti-diabetic drugs [1].

Stage 3 is the stage where overt DM is associated with mild complications. Stage 2 comprises of subjects having mild complications, like low levels of albumin in urine and mild diabetic changes in retina (like microaneurysms, few haemorrhages) [10-12]. These subjects might present with increased blood glucose, or normal value of fasting/2 $\mathrm{h}$ plasma insulin or pro-insulin or C-peptide when OGTT is performed [13, 14]. Aim of management again remains the control of high sugar levels with the use of oral anti-diabetic drugs/insulin along with delaying the development of DM complications, besides basic lifestyle interventions, use of ACE inhibitors if required. Further, prevent or delay the onset and progression of diabetic nephropathy [15-18].

Stage 4 is a stage in DM where insulin is practically non-existent. Stage 4 comprises of subjects having raised blood sugar (BS), almost complete absence of insulin as is reflected by both clinical and laboratory testing. This condition may be associated with mild to moderate disorders like diabetic nephropathy without renal failure or proliferative diabetic retinopathy (PDR) [10, 19, 20].

On testing for fasting plasma insulin or pro-insulin or C-peptide, they are found to be lower as compared to normal lower limit of the reference laboratory, or ratio of fasting glucose to insulin or pro-insulin or C-peptide on OGTT might be considered [6].

In this group for achieving the required blood glucose control goal, ideally, insulin is proper therapy. While treating with insulin in combination with oral hypoglycaemics, warning of hypoglycemia are at (BS) level $<80 \mathrm{mg}$ increased insulin seen, with BS level $<70 \mathrm{mg} \%$ increased glucagon is observed, with BS level $<60 \mathrm{mg} \%$ increased autonomic nervous symptoms are the presenting symptoms and with BS level < $50 \mathrm{mg} \%$ cognitive dysfunctions present, once glucose falls to < $40 \mathrm{mg} \%$ patient becomes drowsy, below $30 \mathrm{mg} \%$ goes into coma, left untreated under $20 \mathrm{mg} \%$ convulsion results and finally $<10 \mathrm{mg} \%$ patient dies. Thus immediate measures required are to give some oral glucose (2-3 tablespoon full of plain glucose in water but not in milk or fruit juice or if possible give immediate intravenous $10 \%$ dextrose as per the severity. Further, the aim is treat other diseases, monitor for development of DM complications and delay them as late as possible.

Stage 5 is the stage where DM is present with advanced complications. This group of patients were present with hyperglycemic crisis and micro/macrovascular problems. Here subjects may have very high blood glucose associated 
with fasting insulin levels or pro-insulin that are either greater or lesser than the levels considered to be normal and same for C-peptide (Table 1).

\begin{tabular}{|c|c|c|c|}
\hline Stage & $\begin{array}{l}\text { Blood Glucose and Insulin } \\
\text { Check }\end{array}$ & Clinical Problems & Aim of management \\
\hline $\begin{array}{l}\text { I } \\
\text { Prediabetes }\end{array}$ & $\begin{array}{l}\text { FSG } 100-125 \mathrm{mg} / \mathrm{dl}(5.6-6.6 \\
\mathrm{mM} \text { (IFD) or } 2 \mathrm{~h} \text { PG on OGTT } \\
140-199 \mathrm{mg} / \mathrm{dl}(7.8-11.0 \mathrm{~mm}) \\
\text { (impaired glucose tolerance) or } \\
\text { HbA1c } 5.7-6.4 \%\end{array}$ & $\begin{array}{l}\text { With or without other } \\
\text { diseases } \\
\text { hypertension, } \\
\text { dyslipidemia/obesity }\end{array}$ & $\begin{array}{l}\text { Reducing rate of T2DM } \\
\text { basic action (diabetes } \\
\text { education, nutritional advice, } \\
\text { exercise, check glucose) Rx } \\
\text { of comorbidities }\end{array}$ \\
\hline $\begin{array}{l}\text { II } \\
\text { Diabetes } \\
\text { Mellitus (no } \\
\text { complications) }\end{array}$ & $\begin{array}{l}\mathrm{HbA} 1 \mathrm{c}>=6.5 \% \text { or } \mathrm{FSG}>=126 \\
\mathrm{mg} / \mathrm{dl}(7.0 \mathrm{~mm}) \text { or } \mathrm{BS}>=200 \\
\mathrm{mg} / \mathrm{dl}(11.1 \mathrm{~mm}) \text { in patient with } \\
\text { classic symptoms of } \\
\text { hyperglycemia }\end{array}$ & $\begin{array}{l}\text { With or without classic } \\
\text { symptoms of } \\
\text { hyperglycemia or sign of } \\
\text { IR }\end{array}$ & $\begin{array}{l}\text { Glycaemic control } \\
\text { Rx other diseases, oral anti- } \\
\text { diabetic drugs, may need } \\
\text { insulin }\end{array}$ \\
\hline $\begin{array}{l}\text { III } \\
\text { Diabetes } \\
\text { Mellitus (with } \\
\text { mild } \\
\text { complications) }\end{array}$ & $\begin{array}{l}\text { Hyperglycemia and/or higher/nor } \\
\text { levels of fasting plasma insulin } \\
\text { /pro-insulin or C-peptide }\end{array}$ & $\begin{array}{l}\text { Microalbuminuria, mild } \\
\text { diabetes retinopathy } \\
\text { (microaneurysms, mild } \\
\text { haemorrhage) }\end{array}$ & $\begin{array}{l}\text { Glycaemic control/delay } \\
\text { diabetes complications, basic } \\
\text { interventions, Rx other } \\
\text { diseases, oral anti-diabetic } \\
\text { drugs/insulin, ACE inhibitors }\end{array}$ \\
\hline $\begin{array}{l}\text { IV } \\
\text { Diabetes } \\
\text { Mellitus (with } \\
\text { absolute } \\
\text { insulin } \\
\text { deficiency) }\end{array}$ & $\begin{array}{l}\text { Hyperglycemia and absolute } \\
\text { insulin deficiency based on } \\
\text { clinical and/or fasting plasma } \\
\text { insulin/pro-insulin or C-peptide } \\
\text { lower than normal limit of lab or } \\
\text { level of } 2 \text { h plasma insulin or pro- } \\
\text { insulin or C-peptide during } \\
\text { OGTT < } 5 \text { times of pts fasting } \\
\text { plasma insulin or pro-insulin or } \\
\text { C-peptide }\end{array}$ & $\begin{array}{l}\text { Mild-moderate } \\
\text { complications like } \\
\text { diabetes nephropathy } \\
\text { without kidney failure, } \\
\text { diabetes retinopathy } \\
\text { without proliferative } \\
\text { diabetic retinopathy }\end{array}$ & $\begin{array}{l}\text { Glycaemic control/delay } \\
\text { Rx diabetes complications, } \\
\text { basic interventions, Rx other } \\
\text { disease monitor } \\
\text { complications, oral anti- } \\
\text { diabetic drugs and insulin }\end{array}$ \\
\hline $\begin{array}{l}\text { V } \\
\text { Diabetes } \\
\text { Mellitus (with } \\
\text { advanced } \\
\text { complications) }\end{array}$ & $\begin{array}{l}\text { Hyperglycemia or } \\
\text { higher/lower/normal levels of } \\
\text { fasting plasma insulin or C- } \\
\text { peptide }\end{array}$ & $\begin{array}{l}\text { Hyperglycemic crises, } \\
\text { diabetic ketoacidosis, } \\
\text { hyperosmolar } \\
\text { hyperglycaemic state, } \\
\text { microvascular, } \\
\text { neovascularization } \\
\text { preretinal vitreous } \\
\text { haemorrhage, } \\
\text { neuropathy (sensory foot } \\
\text { lesions, autonomic } \\
\text { nervous system, sexual } \\
\text { dysfunction, } \\
\text { cardiomyopathy), } \\
\text { macrovascular (coronary } \\
\text { heart disease, } \\
\text { cardiovascular disease, } \\
\text { peripheral artery disease) }\end{array}$ & $\begin{array}{l}\text { Glycaemic control and delay } \\
\text { Rx diabetes complications, } \\
\text { Rx with oral anti-diabetic } \\
\text { drugs (insulin) }\end{array}$ \\
\hline
\end{tabular}

Table 1: Proposed staging of type 2 diabetes mellitus (T2DM). 
The most damaging complications in T2DM are diabetic ketoacidosis (DKA) and hyperosmolar hyperglycemic state (HHS). Diagnosis for DKA requires a level of PG to be more than $250 \mathrm{mg} / \mathrm{dL}$ associated with a low $\mathrm{pH}$ in the arteries with a level < 7.30, and serum bicarbonate levels lower than $18 \mathrm{mEq} / \mathrm{L}$ and presence of both urinary and serum ketones like acetoacetic acid beta-hydroxybutyric acid. The diagnostic criteria for HHS include PG level higher than $600 \mathrm{mg} / \mathrm{L}$, arterial $\mathrm{pH}$ over 7.30, and serum bicarbonate levels more than $18 \mathrm{mEq} / \mathrm{L}$, and the ultimate osmolality in blood over $320 \mathrm{mOsm} / \mathrm{kg}$, resulting in a semi-conscious or comatose state [21, 22].

Complications which involve the smaller vessels are retinopathy (secondary to development of new vessels in the retina resulting in either vitreous or preretinal bleed), renal impairments, nerves involvement [at sensory level with a history of foot lesions being part of this stage along with a variety of autonomic dysfunctions which might cause erectile dysfunctions like impotence and altered motility of stomach and gastrointestinal tract (GIT)] and dilated heart. At macro level, complications are in the coronary arteries that may cause myocardial infarction in the blood supply of the central nervous system (CNS) which might result in a stroke, proliferated blood vessels in retina secondary to DM referred to as PDR which may cause loss of vision [23], peripheral arterial involvement specially of the foot that ultimately may land the subject in gangrene, amputation of foot along with non-healing foot ulceration [5, 6].

Further, we had reviewed the importance of combining SGLT2 inhibitors with metformin as initial treatment for T2DM and advantages of oral fixed drug pill like empagliflozin/metformin in patients with cardiovascular and renal risk for getting better glycaemic control as early as possible [24].

Pfohl et al. [25] aimed to find out predictors of long-term response to the initiation of basal-supported oral therapy (BOT) with insulin glargine (IGlar-100). Patients from the observational titration and optimisation (TOP) registry were grouped into those who had achieved (responders) and who had not achieved (non-responders) their HbA1c target and FBG $\leq 110 \mathrm{mg} / \mathrm{dL} 12$ months after IGlar-100 initiation. Independent predictors of treatment response were identified by regression analysis. Data for 2444 patients were analyzed (responders: $\mathrm{n}=1610$; non-responders: $\mathrm{n}=$ 834). Though the IGlar-100 dose increase over 12 months was large for non-responders $(+12.83$ vs. $+9.46 \mathrm{U} / \mathrm{d}$; $\mathrm{p}<$ $0.0001)$, the corresponding reduction in HbA1c was smaller (-0.88\% vs. $-1.57 \%)$. Independent predictors of response included a lower BMI (Odds Ratio, 0.97; 95\% CI, 0.95-1.00), lower FBG (OR, 0.98; 95\% CI, 0.97-0.98) and HbA1c values at bedtime (OR, 0.24; 95\% CI, 0.18-0.31), a more lenient HbA1c target (OR, 5.07; 95\% CI, 3.37-7.63) and bedtime administration of IGlar-100 (OR, 1.55; 95\% CI, 1.12-2.14). Thus concluding, HbA1c was the clinical most significant baseline characteristic predictive of response to BOT. This might implicate an advantage for IGlar-100 initiation prior to excessive hyperglycemia escalation.

\section{Conclusion}

With the increasing incidence of obesity and a corresponding increase in T2DM, more awareness is needed to treat diabesity simultaneously. Preferably, one should attempt to treat DM with weight neutral anti-diabetics or liraglutide which has weight losing properties. Initially, insulin should be avoided as far as possible due to its weight increasing properties. Further, once T2DM is diagnosed; one needs to see the severity of the disease. Hence, the need for approaching the patient stage-wise both for the clinician, to understand the significance of how seriously it needs to be taken and for the patient to prevent the development of complications both micro and macrovascular like proliferative retinopathy, nephropathy, renal failure, diabetic gangrene, diabetic foot along with the prevention of the development of life threatening conditions like DKA, severe hypoglycemia and thus avoiding both morbidity and mortality associated with T2DM.

\section{References}

1. Kaur KK, Allahbadia GN, Singh M. Importance of simultaneous treatment of obesity and diabetes mellitus: A sequelae to the understanding of diabesity-A review. Obes Res Open J. 2019;6(1):1-10.

2. Kaur KK, Allahbadia GN, Singh M. "A comprehensive review explaining the detailed mechanism of actions of various lentils like soya beans, chickpeas in improving insulin resistance”. Acta Scientific Nutritional Health. 2019;3(4):1-13. 
3. Kaur KK, Allahbadia GN, Singh M. Monoterpenes -A class of Terpenoid group of natural products as a source of natural antidiabetic agents in the future -A review. CPQ Nutrition. 2019;3(4),01-21.

4. Wu SL. Staging of type2 diabetes mellitus. GMR. 2015;14(1):2118-21.

5. Genuth S, Alberti KG, Bennett P, et al. Follow-up report on the diagnosis of diabetes mellitus. Diabetes Care. 2003;26(11):3160-67.

6. Sacks DB, Arnold M, Bakris GL, et al. Guidelines and recommendations for laboratory analysis in the diagnosis and management of diabetes mellitus. Clin Chem. 2011;57(6):e1-e17.

7. Reaven GM. Banting lecture 1988. Role of insulin resistance in human disease. Diabetes. 1988;37(12):1595607.

8. American Diabetes Association. Standards of Medical Care in Diabetes-2010. Diabetes Care. 2010;33(S1):S11-S61.

9. Expert Committee on the Diagnosis and Classification of Diabetes Mellitus. Report of the expert committee on the diagnosis and classification of diabetes mellitus. Diabetes Care. 1997;20(7):1183-97.

10. Ciulla TA, Amador AG, Zimman B. Diabetic retinopathy and diabetes macular edema: pathophysiology screening, and novel therapies. Diabetes Care. 2003;26(9):2653-64.

11. Lu J, Ma X, Zhang L, et al. Glycaemic variability assessed by continuous glucose monitoring and the risk of diabetic retinopathy in latent autoimmune diabetes of the adult and type 2 diabetes. J Diabetes Investig. 2019;10(3):753-59.

12. Levey AS, Coresh J, Balk E, et al. National kidney foundation practice guidelines for chronic kidney disease: evaluation, classification, and stratification. Ann Intern Med. 2003;139(2):137-47.

13. Chiasson JL, Josse RG, Gomis R, et al. Acarbose for prevention of type 2 diabetes mellitus: the STOPNIDDM randomized trial. Lancet. 2002;339(9323):2072-77.

14. Nathan DM, Davidson MB, DeFranzo RA, et al. Impaired fasting glucose and impaired glucose tolerance: implications for care. Diabetes Care. 2007;30(3):753-59.

15. Tanaka S, Tanaka S, Iimura S, et al. Predicting macro- and microvascular complications in type 2 diabetes mellitus: the Japan diabetes complication study/ the Japanese elderly diabetic interventions trial risk engine. Diabetes Care. 2013;36(5):1193-99.

16. Rigalleau V, Cougnard-Gregorie A, Nov S, et al. Association of advanced glycation end products and chronic kidney disease with macroangiopathy in type 2 diabetes. J Diabetes Complications. 2015;29(2):270-74.

17. Elksnis A, Martinell M, Eriksson O, et al. Heterogeneity of metabolic defects in type 2 diabetes and its relation to reactive oxygen species and alterations in beta-cell mass. Front Physiol. 2019;10(107):1-13.

18. Karalliedde J, Gnudi I. Diabetes mellitus, a complex and heterogeneous disease, and the role of insulin resistance as a determinant of diabetic kidney disease. Nephrol Dial Transplant. 2016;31(2):206-13.

19. Fong DS, Aiello L, Gardner TW, et al. Retinopathy in diabetes. Diabetes Care. 2004; 27(S1):S84-S87.

20. KDOQI clinical practice guidelines and clinical practice recommendations for diabetes and chronic kidney disease. Am J Kidney Dis. 2007;49(S2):S12-S154. 
21. Kim S. Burden of hospitalization primarily due to uncontrolled diabetes: implications of inadequate primary health in the United States. Diabetes Care. 2007;30(5):1281-82.

22. Kitabchi AE, Umpierrez GE, Miles JM, et al. Hyperglycemic crisis in adult patients with diabetes. Diabetes Care. 2009;32(7):1335-43.

23. Kaur KK, Gopalan S. Pregnancy with proliferative diabetic retinopathy-a case report. PGI Bulletin. 1986.

24. Kaur KK, Allahbadia GN, Singh M. Role of combination therapy with SGLT2 inhibitor with metformin as initial treatment for type 2 diabetes- Advantages of oral fixed drug pill like empagliflozin/metformin in patients with cardiovascular and renal risk-A short communication. Archives of Diabetes and Endocrine System. 2019;2(1):15-19.

25. Pfohl M, Pscherer S, Fritsche A, el al. Predictors of treatment response in type-2 diabetes patients initiating basal-supported oral therapy with insulin glargine 100U/ml: A sub-analysis of Titration and OPtimisation (TOP) registry. Diabetes Obes Metab. 2019. 